\title{
The rhenium isotope composition of Atlantic Ocean seawater
}

\author{
Alexander J. Dickson ${ }^{1}$, Yu-Te Hsieh², Allison Bryan²
}

1. Department of Earth Sciences, Royal Holloway University of London, Egham, Surrey, TW20 OEX

2. Department of Earth Sciences, University of Oxford, South Parks Road, Oxford, OX1 3AN

\section{Abstract}

The concentrations and isotopic compositions of rhenium are presented from seawater samples obtained from the primary station for the Bermuda Atlantic Time Series Study in the North Atlantic Ocean and from the $40^{\circ} \mathrm{S}$ UK GEOTRACES expedition in the South Atlantic Ocean. Salinitynormalized $\mathrm{Re}$ concentrations in both locations range between $\sim 6.8-7.7 \mathrm{ppt}$ between $50-5000 \mathrm{~m}$ depth, consistent with previously published concentration data from the North Atlantic and North Pacific Oceans. Rhenium isotope values (expressed as $\delta^{187 / 185} \mathrm{Re}$ relative to NIST 3143) exhibit minimal variation around an average value of $-0.17 \pm 0.12 \%$ ( $n=12,2$ S.D.), irrespective of water depth or water mass. These results confirm that the isotopic composition of perrhenate $\left(\mathrm{ReO}_{4}{ }^{-}\right)$in seawater is uniform. The new data establish a baseline for evaluating the isotopic mass balance of $\mathrm{Re}$, and for future assessments of whether this global cycle can be disturbed by changes in seafloor redox and/or global weathering rates.

\section{Introduction}

The transition metal rhenium is useful for tracing the evolution of Earth's environmental systems over geological time. Rhenium is highly enriched over its typical continental crust concentration of 0.198 $\mathrm{pg} / \mathrm{g}$ in sedimentary deposits accumulating in reducing settings (Peucker-Ehrenbrink and Jahn, 2001). These high sedimentary enrichments, which are typically the most pronounced of any redoxsensitive element (Brumsack, 2006), have been suggested to occur either due to the reduction of $\operatorname{Re}(\mathrm{VII})$ to $\operatorname{Re}(\mathrm{IV})$ (Colodner et al., 1993; Chappaz et al., 2008), the thiolation of $\operatorname{Re}(\mathrm{VII})-\mathrm{S}$ species, or co-precipitation with Fe-Mo-S phases (Helz and Dolor, 2012; Vorlicek et al., 2012) near to the $\mathrm{Fe}(\mathrm{III}) / \mathrm{Fe}$ (II) redox couple (McKay et al., 1997; Morford et al., 2005, 2009).

Rhenium has two isotopes, ${ }^{187} \mathrm{Re}$ and ${ }^{185} \mathrm{Re}$, which comprise $\sim 63 \%$ and $37 \%$ of natural $\operatorname{Re}$ respectively (Gramlich et al., 1973). Net isotopic fractionation (mass dependent and nuclear volume) of up to $1.5 \%$ is predicted to occur between thiolated $\operatorname{Re}(\mathrm{VII})-\mathrm{S}$ and reduced $\operatorname{Re}(\mathrm{IV})$ species, and the perrhenate $\left(\mathrm{ReO}_{4}{ }^{-}\right)$that is the dominant species of $\mathrm{Re}$ in oxygenated seawater, with $\mathrm{ReO}_{4}{ }^{-}$having the highest isotopic composition (Miller et al., 2009, 2015). The removal of mass of Re with a lower isotopic composition than seawater into marine sediments accumulating in low-oxygen conditions would have the potential to alter the global seawater isotopic composition if these fluxes changed over geological time. This effect is the basis for the possible application of Re isotopes as a tracer 
of global ocean redox, in a similar vein to molybdenum, uranium and thallium isotopes, among others (e.g. Stirling et al., 2008; Anderson et al., 2014; Owens et al., 2016; Kendall et al., 2017).

Conversely, the isotopic composition of Re in the oceans may also be perturbed by a change in the size or compositions of the input flux. The pre-anthropogenic global riverine Re concentration is $\sim 11.2 \mathrm{pmol} / \mathrm{kg}$ (Colodner et al., 1993; Miller et al., 2011), yielding an annual flux to the oceans of $\sim 4.3 \times 10^{5} \mathrm{~mol} / \mathrm{yr}$ (Miller et al., 2011). This riverine flux is suggested to be largely controlled by the oxidation of organic carbon and sulfides from terrestrial rocks, as indicated by the close correspondence between dissolved $\mathrm{Re}$ and $\mathrm{SO}_{4}{ }^{2-}$ concentrations in rivers globally (Miller et al., 2011), by the close correspondence between Re and organic carbon concentrations in oxidatively weathered soil and shale profiles (Peucker Ehrenbrink and Hannigan, 2000; Hilton et al., 2014), and by the high concentrations of Re associated with n-alkane insoluble organic compounds (Selby et al., 2007). Changes to the locus of Re weathering, from organic-rich to silicate rocks, could thus alter the size and compositions the Re flux to the oceans (Miller et al. 2015; Dellinger et al., 2020).

Unfortunately, the development of the Re isotope system as a proxy for either ocean redox or weathering is currently hindered by a lack of data on the various parts of the modern Re cycle: seawater, weathering fluxes, and sedimentary removal fluxes. This paper presents isotopic measurements of dissolved Re in seawater from two vertical profiles in the North and South Atlantic Oceans. These samples span a range of water masses sourced from distinct oceanic regions. Thermodynamic calculations predict that Re should exist in oxygenated seawater as the stable oxyanion perrhenate $\left(\mathrm{ReO}_{4}^{-}\right)$(Brookins, 1986). The concentration of $\mathrm{Re}$ in seawater has previously been determined to fall in the range $\sim 7.29-8.19 \mathrm{pg} / \mathrm{g}(\sim 39-44 \mathrm{pM})$, with a relationship with salinity that confirms its generally conservative behaviour (Anbar et al., 1992; Colodner et al., 1993). The intention here is to characterize the isotopic signature of $\mathrm{ReO}_{4}^{-}$in seawater; and to test whether this isotope signature is the same in different water masses. These data are an important first step to understanding the global isotopic mass balance of $\mathrm{Re}$, and the processes that might cause this balance to change over geological timescales.

\section{Methods}

Samples were collected from the UK Geotraces $40^{\circ} \mathrm{S}$ expedition (GA10) and from the primary station of the Bermuda Atlantic Timeseries Study (BATS). Exact sample positions are noted in Fig. 1. Seawater samples were collected using either a stainless steel (BATS) or titanium (GEOTRACES) rosette, each equipped with 24 Ocean Test Equipment sampling bottles. Seawater was filtered on board into acid-cleaned HDPE containers using $0.2 \mu \mathrm{m}$ AcroPak $^{\mathrm{TM}}$ polyethersulfone filters and acidified immediately with a small amount of distilled $\mathrm{HCl}$ to reach $\mathrm{pH} \sim 1.7$.

For Re concentrations, $\sim 20 \mathrm{ml}$ of filtered seawater was weighed directly into a Teflon vial and spiked with a ${ }^{185} \mathrm{Re}$-enriched spike solution. Vials were sealed and allowed to reflux for 24 hours to achieve spike-sample equilibrium. Subsequently they were evaporated to dryness, refluxed in a 3:1 mixture of concentrated $\mathrm{HNO}_{3}$ and $\mathrm{HCl}$, evaporated again to dryness and re-dissolved in $2 \mathrm{ml} 0.2 \mathrm{M}$ 
$\mathrm{HNO}_{3}$. Re was purified from the seawater matrix using a small anion exchange column. The sample was loaded onto $200 \mu \mathrm{l}$ clean, pre-conditioned AG1-X8 anion resin (200-400 mesh). Matrix elements were eluted using a further $2 \mathrm{ml} 0.2 \mathrm{M} \mathrm{HNO}_{3}$, before Re was eluted with $2 \mathrm{ml} 8 \mathrm{M} \mathrm{HNO}_{3}$. Two different ${ }^{185} \mathrm{Re}$ spikes were used in the course of this study. For samples processed at the University of Oxford, the DTM (Department of Terrestrial Magmatism, Washington, USA) Re spike was used. For samples processed at Royal Holloway, a new spike solution was prepared from metal powder obtained from Oakridge National Laboratories. Full details of the spike calibration procedure and results are described in the supplementary information.

For $\mathrm{Re}$ isotopes, $\sim 500 \mathrm{ml}$ of water from each sample was evaporated dry in a class 10 laminar flow hood, and re-dissolved in $120 \mathrm{ml} 0.25 \mathrm{M} \mathrm{HCl}$. Procedural blanks were spiked with the RHUL ${ }^{185} \mathrm{Re}$ tracer and re-dissolved in the same volume of acid. Re was purified from matrix elements with a two-step column procedure. First, samples were loaded onto pre-cleaned $3 \mathrm{ml}$ AG1-X8 (200-400 mesh) anion exchange resin, with a further addition of $10 \mathrm{ml} 0.25 \mathrm{M} \mathrm{HCl}$ to elute matrix elements. Thereafter, Re was eluted with $28 \mathrm{ml} 8 \mathrm{M} \mathrm{HNO}_{3}$. In the second step, each sample was evaporated to dryness, re-dissolved in $1 \mathrm{ml} 1 \mathrm{M} \mathrm{HF} / 0.5 \mathrm{M} \mathrm{HCl}$ and loaded onto $200 \mu \mathrm{l}$ anion resin in Teflon columns. Matrix elements were eluted with further additions of $1 \mathrm{ml} 1 \mathrm{M} \mathrm{HF} / 0.5 \mathrm{M} \mathrm{HCl}, 1 \mathrm{ml} 4 \mathrm{M} \mathrm{HCl}$ and $0.4 \mathrm{ml} 3 \mathrm{M} \mathrm{HNO}_{3}$. Re was eluted with $1.5 \mathrm{ml} 8 \mathrm{M} \mathrm{HNO}_{3}$. After each Re elution step, resin beads were visible in the Teflon sample vials. To minimize the effect of organic material on mass spectrometry, each sample was dissolved in a small volume of concentrated $\mathrm{HNO}_{3}$ and ultra-pure $\mathrm{H}_{2} \mathrm{O}_{2}$ and refluxed for 48 hours at $120^{\circ} \mathrm{C}$. They were then evaporated dry and re-dissolved in $0.5 \mathrm{ml}$ $3 \% \mathrm{HNO}_{3}$. The mass of $\mathrm{Re}$ recovered after columns was quantified during concentration check measurement runs by comparing a diluted aliquot of each sample to the signal intensities of external standards.

$\mathrm{Re}$ isotope ratios were measured in two laboratories. Several of the South Atlantic samples were measured at the University of Oxford using a Nu Instruments MC-ICP-MS attached to an ESI Apex sample introduction system with the spray chamber set to $100^{\circ} \mathrm{C}$. This set up was required in order to achieve the requisite sensitivity in wet plasma mode to precisely monitor masses 185 and 187. Samples were introduced as $10 \mathrm{ppb}$ solutions to the instrument in $2 \% \mathrm{HNO}_{3}$. Each measurement comprised a single block of $30 \times 10$ s integrations, preceded by 10 integrations of blank $2 \% \mathrm{HNO}_{3}$ to monitor backgrounds. Washout of Re to background levels between samples took $\sim 5-$ 10 minutes with $10 \% \mathrm{HNO}_{3}$ and $2 \% \mathrm{HNO}_{3}$. Backgrounds rose throughout individual analysis sessions to as high as $\sim 1.5 \%$ of the total analyte signal, but the measured composition of standards throughout the run did not notably change due to the background signal corrections.

Isotope ratios of the BATS samples and replicates of the South Atlantic samples were performed at Royal Holloway using a Neptune Plus MC-ICP-MS fitted with $10^{13} \Omega$ faraday resistors in wet plasma mode, with standard wet-plasma sample cones and ' $H$ ' skimmer cones. Samples were introduced to the instrument as $5 \mathrm{ppb}$ solutions using a quartz SIS spray chamber. Each measurement comprised a single block of $40 \times 8.5 \mathrm{~s}$ integrations, preceded by 10 integrations of 
115 blank $3 \% \mathrm{HNO}_{3}$. Washout of Re to $<0.1 \%$ of the analyte signal was achieved using $3 \% \mathrm{HNO}_{3}$ in $\sim 90$ 116 s.

117 For both setups, instrumental mass bias was corrected by doping each sample to 30 or 40 118 ppb W with NIST SRM 3163. This method offers a robust correction of the variable matrix 119 contributions in each sample solution, given the similar ionization potentials of Re and W and their 120 linearly related instrumental fractionation factors (Miller et al., 2009; Poirier and Doucelance, 2009; 121 Dellinger et al., 2020). The W/Re ratios employed here ( 6-8) were uniform between samples and 122 bracketing standards, and thus do not affect the quality of isotope data via irregular formation of 123 hydrides or peak tailing/abundance sensitivity effects (Dellinger et al., 2020). Measured ratios were 124 corrected for instrumental bias by normalizing to $a^{186} \mathrm{~W} /{ }^{184} \mathrm{~W}$ ratio of 0.92767 and applying this to 125 the measured ${ }^{187} \mathrm{Re} /{ }^{185} \mathrm{Re}$ ratios using an exponential mass bias law (Miller et al., 2009). $\delta^{187 / 185} \mathrm{Re}$ 126 values were then calculated relative to bracketing measurements of NIST SRM 3143: $\delta^{187 / 185} \operatorname{Re}=$ $127\left[\left({ }^{187} \mathrm{Re} /{ }^{185} \mathrm{Re}_{\text {sample }}-{ }^{187} \mathrm{Re} /{ }^{185} \mathrm{Re}\right.\right.$ NIST $\left.\left.) /{ }^{187} \mathrm{Re} /{ }^{185} \mathrm{R} e_{\text {NIST }}\right)\right] * 1000$. The potential interference of ${ }^{187}$ Os on

$128{ }^{187} \mathrm{Re}$ was corrected by simultaneously monitoring ${ }^{189} \mathrm{Os}$ during each static measurement. Inter129 laboratory accuracy of Re isotope data was monitored through the use of several secondary solution 130 standards: an ICP Re concentration standard, a solution of $\mathrm{H}$ Cross company high purity Re wire, 131 NIST SRM 989 and DURH-Re 1. Rhenium isotope ratios of spiked seawater concentration samples 132 were determined from $\sim 250 \mathrm{pg} / \mathrm{g}$ solutions by an identical measurement procedure as for isotope 133 ratios, and calculated by isotope dilution from mass-bias corrected ${ }^{185} \mathrm{Re} /{ }^{187} \mathrm{Re}$ ratios.

\section{Results}

136 The isotopic compositions of Re standard solutions are presented in Table 1 and seawater $\operatorname{Re}$ concentration and isotopic data are presented in Table 2. Seawater concentrations average 7.23 $\mathrm{pg} / \mathrm{g}$ across the entire dataset. Re isotope compositions are uniform within their uncertainties and average $-0.17 \pm 0.12 \%$.

\section{Discussion}

142 Data quality and inter-laboratory accuracy

143 The external reproducibility of Re solution standards improves to $< \pm 0.1 \%$ at analyte concentrations $144>2 \mathrm{ppb}$, while internal 2 S.E. counting uncertainties improve to $< \pm 0.06 \%$ at signal intensities of $>\sim 50$ $145 \mathrm{mV}$ for ${ }^{187} \operatorname{Re}$ (Fig. S2). The low uncertainties at low sample voltages are due to the use of $10^{13} \Omega$ 146 Faraday resistors that increase the signal/noise ratio of small Re beams. For typical measurement 147 concentrations of $4-5 \mathrm{ppb} R$, internal errors are approximately $\pm 0.07 \%$, which are comparable to 148 the results of Dellinger et al. (2020) for similar size sample beams using an identical analytical setup. Measurements of secondary solution standards indicate excellent inter-laboratory accuracy 150 (Table 1). The mean $\delta^{187 / 185}$ Re determined here of NIST SRM 989 relative to NIST SRM 3143, for 151 analyte concentrations $>4 \mathrm{ppb}$, was $-0.26 \pm 0.1 \%$, which is within uncertainty of the value determined by Miller et al. (2009) of $-0.29 \pm 0.07 \%$ and the value determined by Dellinger et al. (2020) of -0.28 
$153 \pm 0.04 \%$. Similarly, a solution of high-purity Re wire obtained from H Cross company by Miller et al.

154 (2009) yielded a $\delta^{187 / 185} \mathrm{Re}$ of $-0.01 \pm 0.12 \%$ (re-normalized to NIST 3143); a different aliquot of H

155 Cross Re wire prepared during this study yielded a composition of $-0.02 \pm 0.1 \%$. Inter-laboratory

156 accuracy is further demonstrated by the similarity in the composition of the DURH-1 Re standard 157 characterized by Dellinger et al. (2020) as $0.16 \pm 0.03 \%$, (relative to NIST 3143) and at Royal 158 Holloway in this study $\left(0.13 \pm 0.04 \%\right.$ ). Finally, the mean $\delta^{187 / 185} \operatorname{Re}$ values of an in-house ICP $\operatorname{Re}$ 159 solution standard analysed at Royal Holloway and Oxford during the course of this study were the 160 same within uncertainties, suggesting that the data produced in both labs is comparable.

161 Procedural blanks, as determined by isotope dilution for concentration and stable isotope 162 measurements, were 4-8 pg, constituting a tiny amount of the total Re processed. Concentration 163 measurements were blank corrected, while isotope measurements were not. Miller et al. (2009), Liu 164 (2015) and Dellinger et al. (2020) showed that $\sim 60 \%$ of Re need to be eluted from AG1-X8 resin 165 with $4 \mathrm{M} \mathrm{HNO}_{3}$ to minimize column fractionation to within an uncertainty of $\pm 0.1 \%$ from the 'true' value. Re recoveries in this study were between $\sim 63 \%$ and $\sim 100 \%$ (Table 2 ), which are large enough to avoid measurable fractionation. In any case, we used $7.5 \mathrm{M} \mathrm{HNO}_{3}$ to elute Re: Dellinger et al. (2020) showed that column fractionation effects are negligible when eluting Re with $8 \mathrm{M} \mathrm{HNO}_{3}$.

\section{Atlantic seawater Re concentration data}

171 The blank-corrected and salinity-normalized concentrations of the BATS seawater samples 172 measured at RHUL range from $6.79-7.42 \mathrm{pg} / \mathrm{g}$, with an average of $7.16 \mathrm{pg} / \mathrm{g}$. These concentrations are similar to those from the South Atlantic measured in the same lab, which range from 6.86-7.42 $\mathrm{pg} / \mathrm{g}$ (average $7.11 \mathrm{pg} / \mathrm{g}$ ). The South Atlantic samples measured in Oxford using the DTM ${ }^{185} \operatorname{Re}$ spike have systematically higher concentrations $(7.51-7.81 \mathrm{pg} / \mathrm{g}$, average $7.58 \mathrm{pg} / \mathrm{g})$ that are probably due to the precision of the calibrated concentrations of the DTM and RHUL ${ }^{185} \operatorname{Re}$ spike solutions. Two samples (BATS $50 \mathrm{~m}$ and BATS $2000 \mathrm{~m}$ ) were measured at RHUL using four separately spiked aliquots of seawater to assess external reproducibility, accounting for the full chemical separation and measurement procedure. These replicates indicate a precision of $\sim 4-7 \%$ on the calculated concentrations. The apparent difference in the seawater concentrations measured on the same samples at RHUL and Oxford is therefore not resolvable outside of the uncertainties.

The average concentration of all BATS samples is $7.16 \pm 0.34 \mathrm{pg} / \mathrm{g}$ (2 S.D.), and the average of the South Atlantic samples is $7.58 \pm 0.25 \mathrm{pg} / \mathrm{g}$. The variability in the entire dataset $(\sim 5 \%)$ is close to that of the sample replicates, thus suggesting that most of the inter-sample variation is related to procedural uncertainties (determination of ${ }^{185} \mathrm{Re} /{ }^{187} \mathrm{Re}$ ratios, procedural blanks, spike-sample equilibration) rather than variation within the water column. Concentrations are therefore invariant with depth (Fig. 1). The mean Re concentrations determined in this study are close to the mean concentration of $7.42 \pm 0.04$ pg/g for North Pacific seawater measured by Anbar et al. (1992) and thus confirm the homogeneity of seawater Re concentrations in different ocean basins. 
Atlantic seawater $\delta^{187 / 185} R e$ compositions

192 The isotopic compositions of seawater determined for the BATS samples range from $-0.07 \pm 0.06$

$193 \%$ to $-0.23 \pm 0.06 \%$, and average $-0.18 \%$. Excluding one anomalously low replicate (> 2 S.D.

194 deviance from the whole dataset), the average is $-0.20 \%$. The Re isotope compositions of the South Atlantic samples range from $-0.08 \pm 0.06 \%$ to $-0.21 \pm 0.06 \%$ and average $-0.14 \%$. As for the $\operatorname{Re}$ concentration data, the BATS and South Atlantic isotope data are therefore not distinguishable outside of the external reproducibility of the method $( \pm 0.07 \%)$ and are uniform with depth. The data provide constraints on the isotopic composition of several major water masses (North Atlantic Deep Water, Circumpolar Deep Water, Antarctic Intermediate Water, Weddell Sea Deep Water) which exhibit significant differences in water mass chemistry based on traditional nutrient tracers (e.g. phosphate concentrations, Fig. 1) but lack any resolvable differences in $\delta^{187 / 185} \mathrm{Re}$. The lack of depthdependency in the data is consistent with evidence that $R e$ is not involved in biological processes and therefore not prone to re-mobilisation within the water column during organic matter production and subsequent oxidation (Pilato and Steifel, 1999).

The Atlantic seawater Re-isotope composition determined here can be considered representative of the stable perrhenate ion $\mathrm{ReO}_{4}{ }^{-}$that constitutes the vast majority of $\mathrm{Re}$ in the oceans under typical Eh-pH conditions (Brookins, 1986; Anbar et al., 1992; Colodner et al., 1993; Koide et al., 1995). The close agreement between the $\delta^{187 / 185} \operatorname{Re}$ data from natural samples and the $\delta^{187 / 185} \operatorname{Re}$ composition of the IAPSO seawater standard measured by Dellinger et al. (2020) supports this argument. Additional studies of $\delta^{187 / 185} \mathrm{Re}$ in ocean seawater may yet reveal isotopic differences related to the thiolation, reduction, or sorption of Re under low oxygen or ferruginous conditions, as identified for other dissolved trace metals such as Cd (Janssen et al., 2014; Guinoiseau et al., 2018). $A b$ initio calculations of $\delta^{187 / 185} \operatorname{Re}$ for thiolated and reduced $\mathrm{Re}$ species suggest that where such effects are found, they would be liable to produce reaction products with isotopic compositions lower than $\mathrm{ReO}_{4}^{-}$(Miller et al., 2015). Nonetheless, it is unclear if such effects would be detectable in the open ocean given the need for reaction products to be removed from seawater on timescales faster than localized ocean mixing. Such effects might be detectable in marginal marine basins where water renewal rates are low, or in stably low oxygen open ocean environments, perhaps above the sediment water interface of upwelling zones.

Isotopic mass balance of $R e$

Determining the $\delta^{187 / 185} \mathrm{Re}$ composition of oceanic $\mathrm{ReO}_{4}{ }^{-}$provides a starting point for evaluating the isotopic mass balance of Re in the modern ocean. This task is vital as a first step towards understanding what processes might have perturbed the isotopic system in the geological past. Since ab-initio calculations of thiolated and reduced Re species (those likely to be buried in marine sediments) are all isotopically lower than $\mathrm{ReO}_{4}^{-}$(Miller et al., 2015), the likely isotopic composition of crustal weathering must also be $\leq-0.17 \%$ for the Re cycle to achieve steady-state. Figure 2 shows 
229 proportions of $\mathrm{Re}(\mathrm{VII}) \mathrm{O}_{3} \mathrm{~S}^{-}$(with a composition $0.33 \%$ lower than seawater), $\mathrm{Re}(\mathrm{IV}) \mathrm{Cl}_{6}{ }^{2-}$ (with a 230 composition $1.52 \%$ lower than seawater) and 'quantitative' Re removal, with no isotopic 231 fractionation from seawater (as observed in the modern ocean for Mo and $\mathrm{Zn}$ in euxinic settings).

232 These calculations all indicate an input flux composition that is isotopically lower than seawater, but 233 which could theoretically range anywhere from $\sim-0.20 \%$ to $\sim-1.7 \%$.

234 A large proportion of the Re weathered into the oceans is probably sourced from the oxidation 235 of organic matter in sedimentary rocks (Peucker Ehrenbrink and Hannigan, 2000; Hilton et al., 2014). 236 Miller et al. (2015) measured the isotopic composition of Re in samples from a Devonian Shale 237 weathering profile and found that unweathered organic-rich shale had a value of $-0.57 \%$ 238 (renormalized to NIST 3143). Furthermore, basalt standards analysed by Dellinger et al. (2020) 239 average $\sim-0.33 \%$. Both of these studies are consistent with the prediction in Fig. 2 that weathering 240 inputs must have $\delta^{187 / 185}$ Re compositions lower than seawater $(-0.17 \%)$, but neither they nor the 241 new seawater data can be used to make more precise constraints on this composition. It should also 242 be considered that while $\operatorname{Re}(\mathrm{VII})-\mathrm{S}$ and $\operatorname{Re}(\mathrm{IV})$ species are predicted to have lower $\delta^{187 / 185} \operatorname{Re}$ 243 compositions that seawater $\mathrm{ReO}_{4}^{-}$, the potential for $\mathrm{Re}$ to be removed from seawater with a heavy 244 isotopic composition, perhaps by adsorption to organic matter or mineral surfaces, cannot be 245 presently excluded. Lastly, as with all isotope systems, construction of a modern isotopic mass 246 balance for Re proceeds on the assumption that the system is in steady state. However, given the 247 potential for rapid changes in Re weathering and burial over timescales of $10^{3}$ years (e.g. Crusius et 248 al., 1996; Hilton et al., 2014), this condition may not be met in the modern ocean.

249 A significant amount of work is therefore required to establish more precise constraints on 250 the compositions of input and output fluxes of $R e$ to and from the oceans, to allow an improved 251 understanding of how this isotopic system may be utilized to reconstruct oceanic redox and/or 252 weathering processes in the geological past.

\section{Conclusions}

255 Re concentration and $\delta^{187 / 185} \operatorname{Re}$ data are presented from the BATS primary sampling site in the North 256 Atlantic Ocean and from the GEOTRACES $40^{\circ} \mathrm{S}$ (GA10) transect in the South Atlantic Ocean. 257 Vertical differences in Re concentrations are not discernable outside of analytical uncertainties and 258 are close to previous estimates of Re concentrations in Pacific seawater. The $\delta^{187 / 185} \operatorname{Re}$ of the samples average $\sim-0.17 \pm 0.12 \%$ and are invariant vertically and with latitude. This value therefore characterizes the $\mathrm{Re}(\mathrm{VII}) \mathrm{O}_{4}{ }^{-}$that constitutes the majority of dissolved $\mathrm{Re}$ in the oceans and provides a starting point for evaluating the isotopic mass balance of Re. If sedimentary output fluxes of $\operatorname{Re}$ are assumed to have $\delta^{187 / 185} \operatorname{Re}$ compositions lower than seawater (Miller et al., 2015), the weathering input flux of $\operatorname{Re}$ to the oceans can be predicted to also be $<-0.20 \%$. Although a small number of constrains exist on the composition of weathered $\operatorname{Re}$ (Miller et al., 2015; Dellinger et al., 2020), more precise estimates of this parameter must await future measurements of Re in rivers, 
of Re isotopic standard NIST SRM 989, we suggest that future studies of Re isotopes should use NIST SRM 3143 as a zero-delta reference. The isotopic composition of this solution relative to NIST 989 has now been determined in three different laboratories as $+0.29 \%$ (Table 1), and therefore future studies using NIST 3143 will be directly comparable to the pioneering efforts of Miller et al. (2009, 2015) and Dellinger et al. (2020).

\section{Acknowledgements}

We thank Mathieu Dellinger and Bob Hilton for kindly sharing aliquots of NIST 989 and the DUR-Re1 solution standards. We also thank Anthony Chappaz for many fruitful discussions on Re isotopes during the course of this study. AJD acknowledges a Royal Holloway Research Strategy Fund award that supported this work.

\section{References}

Anbar, A.D., Creaser, R.A., Papanastassiou, D.A. and Wasserburg, G.J. (1992), Rhenium in seawater: confirmation of generally conservative behavior. Geochimica et Cosmochimica Acta 56, 4099-4103.

Anderson, M.B., Romaniello, S., Vance, D., Little, S.H., Herdman, R. and Lyons, T.W. (2014), A modern framework for the interpretation of ${ }^{238} \mathrm{U} /{ }^{235} \mathrm{U}$ in studies of ancient ocean redox. Earth and Planetary Science Letters 400, 184-194.

Brookins, D.G. (1986), Rhenium as analog for fissigenic technetium: Eh-pH diagram $\left(25^{\circ} \mathrm{C}, 1\right.$ bar $)$ constraints. Applied Geochemistry A, 513-517.

Brumsack, H-J. (2006), The trace metal content of recent organic carbon-rich sediments: implications for Cretaceous black shale formation. Palaeogeography, Palaeoclimatology, Palaeoecology 232, 344-361.

Chappaz, A., Gobeil, C. and Tessier, A. (2008), Sequestration mechanisms and anthropogenic inputs of rhenium in sediments from eastern Canada lakes. Geochimica et Cosmochimica Acta 72, 6027-6036.

Colodner, D., Sachs, J., Ravizza, G., Turekian, K., Edmond, J. and Boyle, E. (1993), The geochemical cycle of rhenium: a reconnaissance. Earth and Planetary Science Letters 117, 205221.

Crusius, J., Calvert, S., Pedersen, T. and Sage, D. (1996), Rhenium and molybdenum enrichments in sediments as indicators of oxic, suboxic and sulfidic conditions of deposition. Earth and Planetary Sciences Letters 145, 65-78.

Dellinger, M. Hilton, R.G. and Nowell, G.M. (2020), Measurements of rhenium isotopic composition in low-abundance samples. Journal of Analytical Atomic Spectrometry, DOI:10.1039/c9ja00288j.

Gramlich, J.W., Murphy, T.J., Garner, E.L. and Shields, W.R. (1973), Absolute isotopic abundance ratio and atomic weight of a reference sample of rhenium. Journal of Research of the National Bureau of Standards 77A, 691-698.

Guinoiseau, D., Galer, S.J.G. and Abouchami, W. (2018), Effect of cadmium sulfide precipitation on the partitioning of $\mathrm{Cd}$ isotopes: implications for the oceanic $\mathrm{Cd}$ cycle. Earth and Planetary Science Letters 498, 300-308. 
Helz, G.R. and Dolor, M.K. (2012), What regulates rhenium deposition in euxinic basins? Chemical Geology 304-305, 131-141.

Hilton, R.G., Gaillardet, J., Calmels, D. and Birck, J-L. (2014), Geological respiration of a mountain belt revealed by the trace element rhenium. Earth and Planetary Science Letters 403, 27-36.

Janssen, D.L., Conway, T.M., John, S.G., Christian, J.R., Kramer, D.I., Pedersen, T.F. and Cullen, J.T. (2014), Undocumented water column sink for cadmium in open ocean oxygen-deficient zones. Proceedings of the National Academy of Sciences USA 111, 6888-6893.

Liu, R. (2015), Rhenium isotopic compositions of iron meteorites. MSc Thesis, Florida State University.

McKay, J.J., Pedersen, T.F. and Mucci, A. (2007), Sedimentary redox conditions in continental margin sediments (NE Pacific)- influence on the accumulation of redox-sensitive trace metals. Chemical Geology 238, 180-196.

Kendall, B., Dahl, T.W. and Anbar, A.D. (2017), The stable isotope geochemistry of molybdenum. Reviews in Mineralogy and Geochemistry 82, 683-732.

Koide, M., Hodge, V.F., Yany, J., Stallard, M., Goldberg, E., Calhoun, J. and Bertine, K. (1986), Some comparative marine geochemistries of rhenium, gold, silver and molybdenum. Applied Geochemistry 1, 705-714.

Miller, C.A., Peucker-Ehrenbrink, B. and Ball, L. (2009), Precise determination of rhenium isotope composition by multi-collector inductively-coupled plasma mass spectrometry. Journal of Analytical Atomic Spectrometry 24, 1069-1078.

Miller, C.A., Peucker-Ehrenbrink, B. and Schauble, E.A. (2015), Theoretical modeling of rhenium isotope fractionation, natural variations across a black shale weathering profile, and potential as a paleoredox proxy. Earth and Planetary Science Letters 430, 339-348.

Morford, J.L., Emerson, S.R., Breckel, E.J. and Kim, S.H. (2005), Diagenesis of oxyanions (V, U, Re and $\mathrm{Mo}$ ) in pore waters and sediments from a continental margin. Geochimica et Cosmochimica Acta 69, 5021-5032.

Morford, J.L., Martin, W.R., François, R. and Carney, C.M. (2009), A model for uranium, rhenium and molybdenum diagenesis in marine sediments based on results from coastal locations. Geochimica et Cosmochimica Acta 73, 2938-2960.

Owens, J.D., Nielsen, S.G., Horner, T.J., Ostrander, C.M. and Peterson, L. (2017), Thallium isotopic compositions of euxinic sediments as a proxy for global manganese oxide burial. Geochimica et Cosmochimica Acta 213, 291-307.

Peucker-Ehrenbrink, B. and Hannigan, R.E. (2000), Effects of black shale weathering on the mobility of rhenium and platinum group elements. Geology $28,475-478$.

Peucker-Ehrenbrink, B. and Jahn, B.M. (2001), Rhenium-osmium isotope systematics and platinumgroup elements concentrations: loess and the upper continental crust. Geochemistry Geophysics Geosystems 2, 1061, doi:10.1029/2001GC000172.

Pilato, R.S. and Stiefel, E.I. (1999), Molybdenum and tungsten enzymes. In Reeddijk, J. and Bouwman, E. (eds.), Bioinorganic catalysis 2, 81-152. Marcel Dekker, New York. 
Poirier, A and Doucelance, R. (2009), Effective correction of mass bias for rhenium measurements using MC-ICP-MS. Geostandards and Geoanalytical Research 33, doi:10.1111/j.1751908X.2009.00017.x

Selby, D., Creaser, R.A. and Fowler, M.G. (2007), Re-Os elemental and isotope systematics in crude oils. Geochimica et Cosmochimica Acta 71, 378-386.

Sheen, A.I., Kendall, B., Reinhard, C.T., Creaser, R.A., Lyons, T.W., Bekker, A., Poulton, S.W. and Anbar, A.D. (2018), A model for the oceanic mass balance of rhenium and implications for the extent of Proterozoic ocean anoxia. Geochimica et Cosmochimica Acta 227, 75-95.

Stirling, C.H., Andersen, M.B., Potter, E-K. and Halliday, A.N. (2007), Low-temperature isotopic fractionation of uranium. Earth and Planetary Science Letters 264, 208-225.

Vorlicek, T., Chappaz, A., Groskreutz, L.M., Young, N., Lyons. T.W. (2015), A new analytical approach to determining Mo and Re speciation in sulfidic waters. Chemical Geology 403, 52-57.

\section{Figures}

Figure 1: Re concentrations and isotope compositions for (A) the North Atlantic BATS primary site and (B) for the GEOTRACES GA10 $40^{\circ} \mathrm{S}$ transect. The plots to the left of each panel show sample positions superimposed onto water mass dissolved phosphate concentrations extracted from the World Ocean Atlas 2009. Phosphate concentrations are in units of $\mu \mathrm{M}$. Primary water masses are also displayed. Vertical dashed lines indicate the mean isotopic composition and concentration of all seawater samples analysed. NADW: North Atlantic Deep Water. AABW: Antarctic Bottom Water. SACW: South Atlantic Central Water. SAMW: Sub-Antarctic mode Water. AAIW: Antarctic Intermediate Water. WSDW: Weddell Sea Deep Water.

Figure 2: Mass balance model showing the predicted $\delta^{187 / 185} \operatorname{Re}$ composition of Re weathered into the ocean. The calculated weathering compositions (dashed lines) assume a steady-state system and different fractional combinations of sedimentary output fluxes of $\operatorname{Re}$ as (i) $\operatorname{Re}(\mathrm{IV}) \mathrm{Cl}_{6}{ }^{2-}$ and $\mathrm{Re}(\mathrm{VII}) \mathrm{O}_{3} \mathrm{~S}$; and (ii) $\mathrm{Re}(\mathrm{IV}) \mathrm{Cl}_{6}{ }^{2-}$ and 'quantitative' removal of $\mathrm{Re}$ into sediments. These removal species/mechanisms were chosen because they cover the largest isotopic range predicted by ab initio calcuations (Miller et al., 2015), thus yielding the largest possible range of compositions for the input fluxes. Arrows indicate the composition of unweathered shales and basalt standards measured by Miller et al. (2015) and Dellinger et al. (2020) respectively.

\section{Tables}

Table 1: Compilation of standard solutions analysed in this study, Miller et al. (2009) and Dellinger et al. (2020). All $\delta^{187 / 185} \mathrm{Re}$ compositions are referenced to NIST 3143 as the zero delta. Uncertainties are the external reproducibilities calculated from several measurements of each solution and are typically slightly larger than the measured internal errors. 


\begin{tabular}{|c|c|c|c|c|}
\hline Standard & $\begin{array}{c}\text { Average } \pm 2 \text { S.D. (\%o rel. to NIST } \\
\text { 3143), RHUL }\end{array}$ & $\begin{array}{l}\text { Average } \pm 2 \text { S.D. } \\
\text { (\%o rel. to NIST } \\
\text { 3143), OXFORD }\end{array}$ & $\begin{array}{c}\text { Miller et al., } \\
\text { Average } \pm 2 \text { S.D. (\%o rel. } \\
\text { to NIST } 3143) \text {, WHOI }\end{array}$ & $\begin{array}{l}\text { Dellinger et al., } \\
\text { Average } \pm 2 \text { S.D. } \\
\text { (\%o rel. to NIST } \\
\text { 3143), DURHAM }\end{array}$ \\
\hline NIST 3143 & $0 \pm 0.08$ & $0 \pm 0.08$ & 0 & - \\
\hline NIST 989 & $-0.27 \pm 0.10(n=14)$ & - & $-0.29 \pm 0.07$ & $-0.28 \pm 0.04$ \\
\hline ICP $\mathrm{Re}$ & $-0.15 \pm 0.07 \quad(n=21)$ & $\begin{array}{c}-0.19 \pm 0.09 \\
13)\end{array}(n=$ & - & - \\
\hline H Cross Re wire & $-0.02 \pm 0.10(n=9)$ & - & $-0.01 \pm 0.12$ & - \\
\hline DURH-Re 1 & $0.14 \pm 0.03(n=3)$ & - & - & $0.16 \pm 0.03$ \\
\hline
\end{tabular}

416

417

418 Table 2: BATS data.

\begin{tabular}{|c|c|c|c|c|c|}
\hline Sample & Salinity (PSU) & $\begin{array}{c}\text { Re concentration } \\
(\mathrm{pg} / \mathrm{g})\end{array}$ & $\begin{array}{c}\delta^{187 / 185} \operatorname{Re}(\% \text { NIST } \\
3143)\end{array}$ & 2 S.E. & \% Recovery \\
\hline $\begin{array}{l}50 \mathrm{~m} \\
50 \mathrm{~m}\end{array}$ & $\begin{array}{l}36.61 \\
36.61\end{array}$ & $\begin{array}{l}7.01 \\
7.36\end{array}$ & & & \\
\hline $50 \mathrm{~m}$ & 36.61 & 6.79 & & & \\
\hline $50 \mathrm{~m}$ & 36.61 & 6.94 & & & \\
\hline $200 \mathrm{~m}$ & 36.58 & 7.40 & -0.22 & 0.10 & 63 \\
\hline $200 \mathrm{~m}$ & 36.58 & 6.86 & & & \\
\hline $400 \mathrm{~m}$ & 36.50 & 7.18 & -0.23 & 0.06 & 82 \\
\hline $800 \mathrm{~m}$ & 35.29 & 7.11 & -0.21 & 0.06 & 108 \\
\hline $800 \mathrm{~m}$ & 35.29 & 7.20 & & & \\
\hline $1000 \mathrm{~m}$ & 35.09 & 7.10 & -0.19 & 0.06 & 107 \\
\hline $1000 \mathrm{~m}$ & 35.09 & 7.06 & & & \\
\hline $2000 \mathrm{~m}$ & 34.97 & 7.31 & & & \\
\hline $2000 \mathrm{~m}$ & 34.97 & 7.03 & & & \\
\hline $2000 \mathrm{~m}$ & 34.97 & 7.42 & & & \\
\hline $2000 \mathrm{~m}$ & 34.97 & 7.11 & & & \\
\hline $3000 \mathrm{~m}$ & 34.92 & 7.27 & -0.25 & 0.09 & 85 \\
\hline $3000 \mathrm{~m}$ & 34.92 & 7.38 & -0.07 & 0.06 & 72 \\
\hline $4500 \mathrm{~m}$ & 34.88 & 7.13 & -0.21 & 0.06 & 88 \\
\hline $4500 \mathrm{~m}$ & 34.88 & 7.41 & & & \\
\hline
\end{tabular}

422 Table 3: 40S GEOTRACES GA10 data. Samples marked with an asterisk are from Oxford. All other

423 samples were analysed at RHUL.

\begin{tabular}{|c|c|c|c|c|c|c|}
\hline $\begin{array}{l}\text { GEOTRACES } \\
\text { Bottle code }\end{array}$ & $\begin{array}{c}\text { Water } \\
\text { depth }(m)\end{array}$ & $\begin{array}{l}\text { Salinity } \\
\text { (PSU) }\end{array}$ & $\begin{array}{c}\text { Re concentration } \\
(\mathrm{pg} / \mathrm{g})\end{array}$ & $\begin{array}{l}\delta^{187 / 185} \operatorname{Re}(\% 0 \\
\text { NIST 3143) }\end{array}$ & 2 S.E. & \% Recovery \\
\hline $\begin{array}{l}0179 \\
0179\end{array}$ & $\begin{array}{l}51 \\
51\end{array}$ & $\begin{array}{l}34.88 \\
34.88\end{array}$ & $\begin{array}{l}6.96 \\
7.21\end{array}$ & & & \\
\hline 2327 & 58 & 36.72 & 7.09 & -0.21 & 0.06 & 98 \\
\hline 1550 & 97 & 35.26 & 6.86 & & & \\
\hline 1550 & 97 & 35.26 & 7.17 & & & \\
\hline $1550^{*}$ & 97 & 35.26 & 7.55 & & & \\
\hline 2006 & 496 & 34.18 & 7.02 & & & \\
\hline 2006 & 496 & 34.18 & 7.42 & & & \\
\hline $2006^{*}$ & 496 & 34.18 & 7.81 & -0.19 & 0.14 & 70 \\
\hline $2006^{*}$ & 496 & 34.18 & & -0.08 & 0.10 & 72 \\
\hline $2279^{*}$ & 1492 & 34.47 & 7.56 & & & \\
\hline $2276^{*}$ & 1988 & 34.80 & 7.51 & -0.08 & 0.06 & 76 \\
\hline $2269^{*}$ & 2985 & 34.75 & 7.54 & & & \\
\hline $1952^{*}$ & 5103 & 34.67 & 7.67 & -0.14 & 0.15 & 81 \\
\hline
\end{tabular}


435 Figure 1

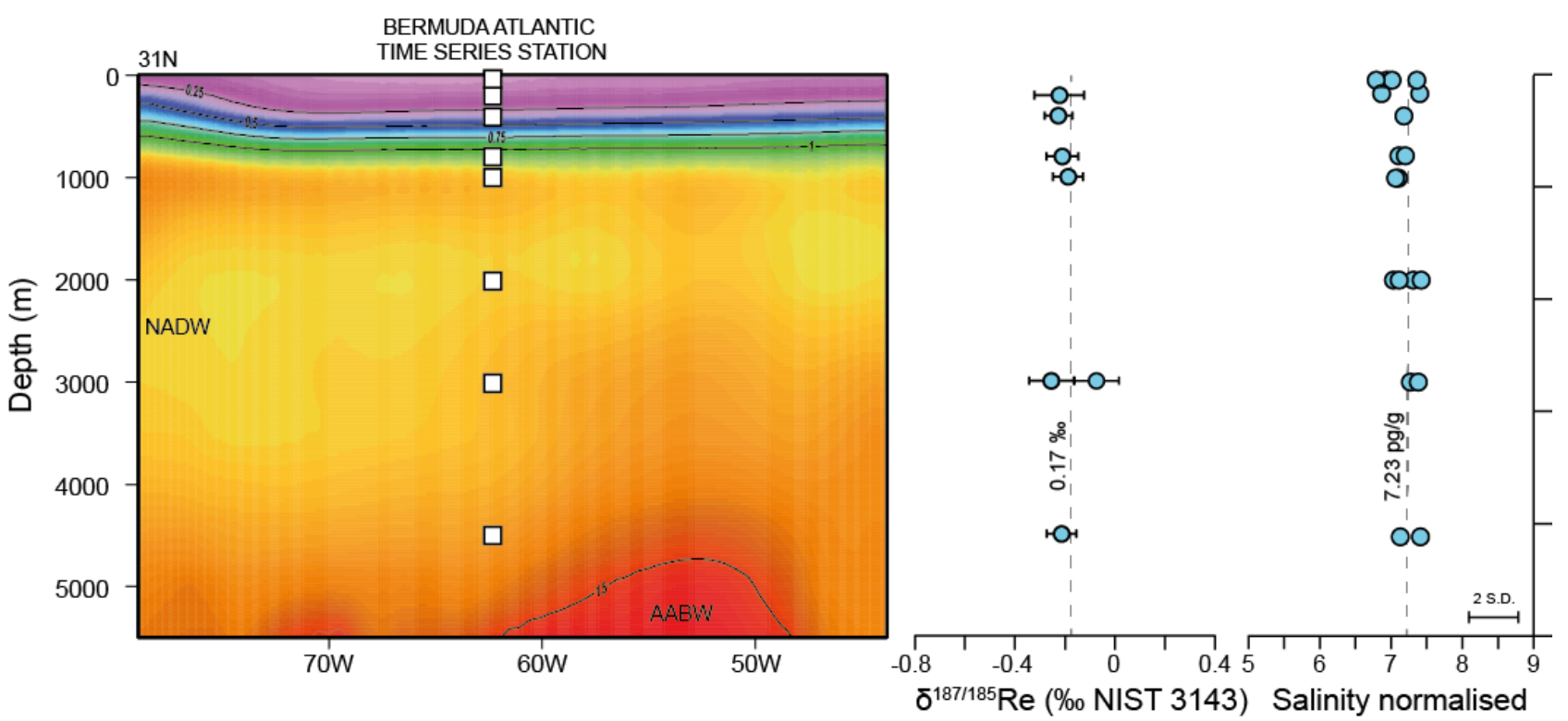

[Re] (pg/g)

ORHUL $\diamond$ OXFORD
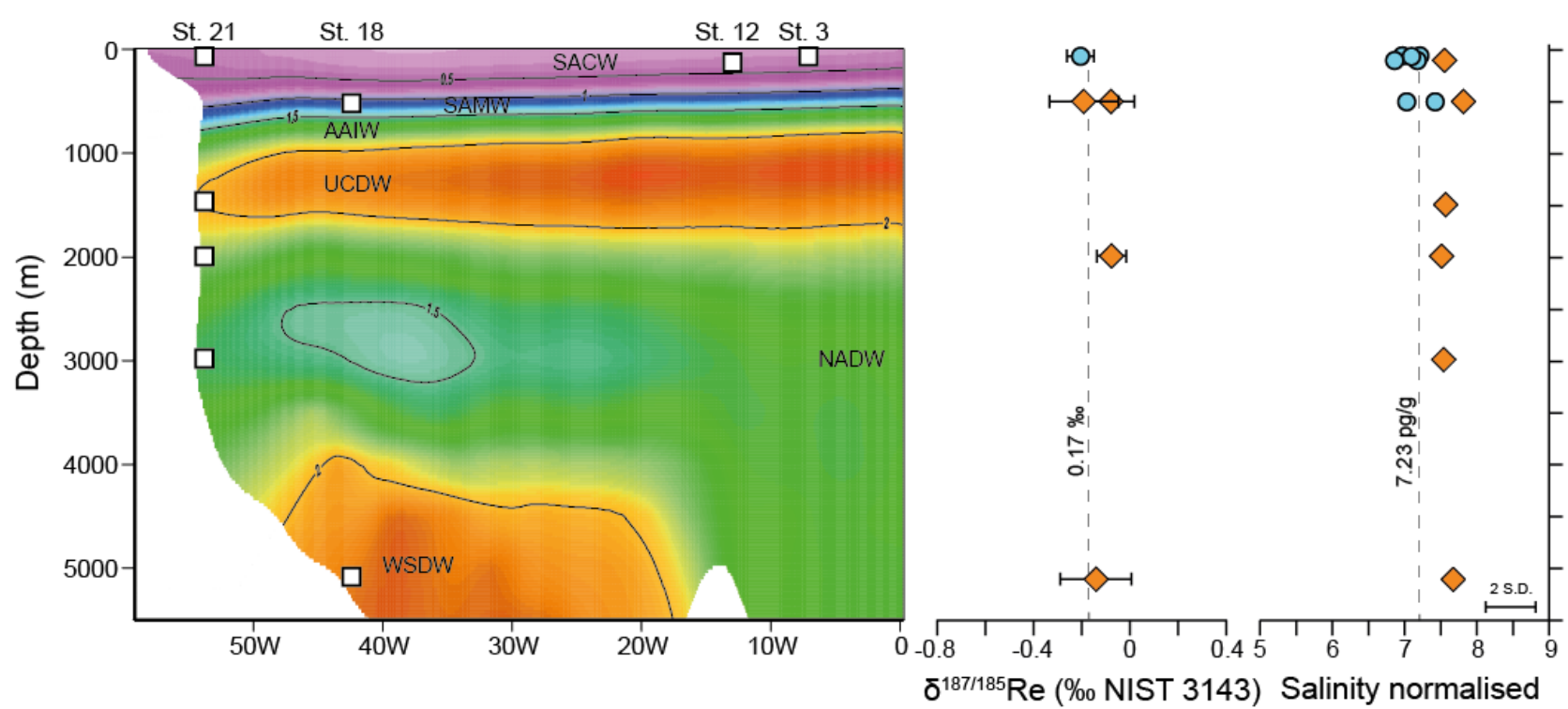
439

440

441

442

443

444

445 Figure 2

446

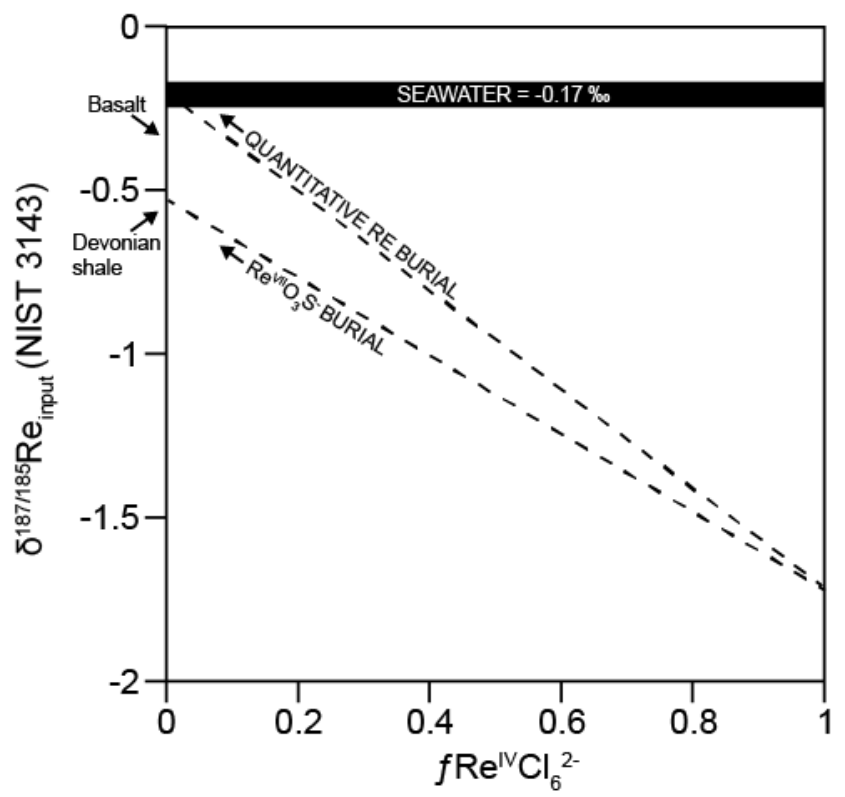

447

448

449

450

451 